\title{
A ECONOMIA MORAL DO \\ RECRUTAMENTO MILITAR NO \\ IMPÉRIO BRASILEIRO*
}

\section{Fábio Faria Mendes}

Dans la guerre, tout est très simple, mais la chose la plus simple est dificile.

(Clausewitz, De la guerre)

Guerra, fricção, administração

A epígrafe acima assinala aquilo que Clausewitz considerava como sendo a razão primeira da diferença entre a guerra dos livros e a guerra real: a presença avassaladora da friç̧ão, conceito que remete à soberania do acaso, do idiossincrático e do imprevisível nas coisas humanas, assim como aos problemas inerentes à agregação e à coordenação de um sem-número de vontades. Para Clausewitz, não há negócio humano que esteja mais sujeito a incerteza do que a guerra. A guerra representa uma situação-limite, uma espécie de "momento metafísico" em que as circunstâncias ordinárias da vida são suspensas pela onipresença do perigo. Os imponderáveis das "forças morais" têm ali papel dominante (Clausewitz,1988, pp. 109113).

O conceito de friç̧ão incorpora, na teoria da guerra, o papel dos erros, dos acidentes, das dificuldades técnicas, do não previsto enfim, e seus efeitos sobre as decisões, a moral e as ações na conduta da guerra. É precisamente o fato de ser a guerra uma forma de intercurso bumano, em que se combinam múltiplas vontades, que introduz em sua lógica a contingência e a imprevisibilidade. Não seria de todo impróprio, portanto, nem contrário ao espírito do autor, estender a aplicação do conceito ao conjunto das relações entre Estado e sociedade. Poderíamos, assim, interpretar os dilemas envolvidos na formação, organização e suprimento dos exércitos como resultantes de modalidades de fricção típicas de certas formas de administração da prestação militar. Quando menos, essa transposição teria a vantagem teórica de chamar a atenção para a tensão inerente à presença de improbabilidades em meio a relações baseadas em certezas e expectativas rotineiras, num esforço contrafenomenológico de ver o Estado não como presença, mas como problema (Luhmann, 1981).

O conceito de fricção é particularmente adequado para caracterizar o jogo de ardis, negociações, resistências e compromissos que caracteriza o recrutamento militar no Brasil imperial, permitindo conceituar a precariedade das 
bases morais e materiais da administração honorária do recrutamento no Brasil do século XIX.

Meu objetivo é interpretar o conjunto de interações que constituem a governança do recrutamento militar no Brasil imperial, estruturado pela combinação da administração bonorária e das ordens de privilégio. Dirijo-me fundamentalmente ao modo de governança das levas forçadas na primeira metade do século XIX. As relações entre Estado e sociedade estruturadas em torno das levas forçadas serão a fonte dos dilemas de mobilização durante a Guerra do Paraguai e das tentativas subseqüentes de reformar a prestação militar.

A forma de friç̧ão característica da administração diletante tem sua origem na profunda incerteza a respeito da colaboração dos notáveis locais com as diretivas do poder central, de realização contingente na letra tanto quanto no espírito. Os problemas de confiança mútua nas relações entre poder central e seus delegados, e deação coletiva na sua mobilização para as rotinas da administração, serão centrais para a compreensão da dinâmica da prestação militar no Brasil imperial. $\mathrm{O}$ argumento desenvolvido aqui é que os dilemas na realização do recrutamento serão resultado de um conjunto de dificuldades práticas inerentes à estrutura de governança honorária (custos de implementação elevados, problemas de informação, problemas de ação coletiva), tanto quanto da oposição de outros atores.

\section{Hierarquias, mercados, liturgias}

No ambicioso projeto de Max Weber de construção de uma sociologia comparada das civilizações, um dos problemas centrais era a compreensão das inúmeras fontes de variação na forma e no espírito das estruturas administrativas, que emergiam como resultado de problemas comuns de delegação de autoridade. Na sua obra, complexas tipologias históricas sobrepostas emergiam das diferenças nos recursos de poder relativos do Príncipe e do quadro administrativo, assim como da variação das formas sagradas e seculares de legitimação do poder (Bendix,
1978). Mais recentemente, autores inspirados pelo "novo institucionalismo" têm procurado compreender a ampla gama de variação nos formatos administrativos dos Estados modernos como resultante das estratégias de maximização de rendimentos de governantes e do quadro administrativo, dos custos de informação e transação das várias alternativas administrativas disponíveis, e do contexto institucional mais amplo (Levi, 1988; Kiser,1994).

Combinando elementos das duas tradições, seria possível construir uma tipologia de modos de governo em queliturgias, mercados e hierarquiasconstituiriam o repertório historicamente disponível de formatos administrativos. Estes formatos operam como mecanismos de coordenação que procuram estabilizar os problemas de integração, coerência e efetividade da regulação estatal. A cada um destes formatos corresponderia uma estrutura de incentivos característica, conformada, respectivamente, por confiança, preços e autoridade (Bradach e Eccles, 1989). Liturgias, mercados e bierarquias conceituam, pois, mecanismos de coordenação alternativos para a realização de rotinas administrativas fundamentais.

Liturgias serão definidas aqui como formas de provisão de serviços administrativos por quaisquer tipos de poderes intermediários com seus próprios recursos. Liturgias implicam prestações administrativas não remuneradas e voluntárias por notáveis locais, conformando o que será conceituado como administração honorária. Sua prática administrativa caracteriza-se pelo diletantismo, pela mobilização de recursos e prestígio próprios, pela cristalização de tradições locais de fixação de gravames, pelo domínio dos processos orais sobre as regras escritas, e pela busca constante de resultados consensuais negociados. Sua operação assemelha-se à lógica dadádiva, numa troca silenciosa em que os obséquios litúrgicos ao poder central supõem retribuições em mercês, auxílios e imunidades. A obediência aos mandatos do poder central será, entretanto, altamente problemática, dada a reduzida especificação da alocação de deveres e obrigações, tanto dos funcionários quanto dos súditos, sujeita a possibilidades sempre presentes de flutuação circunstancial, barganha e traição. 
As diretivas do poder central serão objeto de contínua tradução local pelos notáveis.

Por mercados entende-se simplesmente um modo de provisão de necessidades administrativas que recorre a meios de administração sujeitos a transações de livre compra e venda. Como instrumento de realização de tarefas administrativas, mercados tipicamente envolverão a contratação de empreendedores independentes para prover vários tipos de serviços públicos, quando são indisponíveis, custosos ou ineficazes os meios administrativos à disposição do poder central. Mercados como formatos administrativos serão utilizados em amplo espectro de atividades, tais como a contratação de impostos e monopólios, a venda de cargos e imunidades, o agenciamento de mercenários, a formação e suprimento de exércitos. Na era moderna, dada a fragmentação do uso dos meios de violência, os exemplos mais característicos de formatos administrativos baseados em mercadosconcentrar-se-ão nas tarefas extrativas (Thomson, 1994). Para o poder central, a principal vantagem do uso dos mercados como mecanismo administrativo será a possibilidade de contar com fluxos previsíveis e constantes de rendimentos ou serviços, sem arcar com os custos de extração. Os principais incentivos ao "quadro administrativo" são oferecidos pela possibilidade de maximização dos próprios rendimentos. De modo correspondente, a concorrência entre diversos contratadores e as inúmeras possibilidades de manipulação e superexploração podem resultar em consideráveis efeitos perversos (Büsch, 1997).

Hierarquias, por fim, remetem aos modernos mecanismos burocráticos de implementação de decisões dependentes de funcionários tecnicamente especializados, não proprietários dos meios de administração e remunerados com salários. Tipicamente, os funcionários não se apropriam dos meios técnicos de administração nem dos cargos, são escolhidos em função de considerações técnicas, conduzem-se com base em regras gerais e documentos escritos. As condições especificamente "modernas" da burocracia pressupõem configurações em que se combinam, simultaneamente, o moderno capitalismo racional e a generalização da economia monetária, a concentração de meios técnicos de administração e guerra nas mãos do Estado e a expansão quantitativa e qualitativa das suas funções (Schluchter, 1989).

O Quadro 1 resume as principais características dos três formatos administrativos de nossa tipologia.

Por sua natureza diletante e acessória, a administração através de notáveis locais apresenta limitações técnicas insuperáveis quando se ampliam a extensão quantitativa, a complexidade e a especialização dos negócios administrativos. Vagar nas decisões, menor sujeição a fórmulas, imprevisibilidade e descontinuidade das rotinas administrativas ser-lhe-ão inerentes (Weber, 1986, p. 731).

O domínio do procedimento, a desconsideração das características pessoaise a despreocupação pelas conseqüências, típicos de uma administração racional-legal, serão também totalmente estranhos à administração honorária, limitando, desse modo, as probabilidades de desenvolvimento de um direito eminentemente formal.

Uma estrutura administrativa honorária, ou de funcionários de tipo patrimonial com remuneração emolumental, portanto, estabelece laços de dependência econômica, política e jurídica entre centro e periferia mais mediatizados do que nos quadros administrativos formados por meio de cargos remunerados por salários. De outra parte, ser-lhe-á fundamentalmente necessário contar com a "boa vontade" dos governados para a realização das tarefas administrativas. As obrigações litúrgicas tenderão, pois, a vincular-se a expectativas tradicionais, sob a forma de gravames fixos (Weber, 1986, p. 770). Novas exigências serão interpretadas como uma ruptura no acordo contratual tácito, regulado pelo contexto de uma "economia moral" preexistente. 


\section{Quadro 1}

\begin{tabular}{|c|c|c|c|}
\hline \multicolumn{3}{|c|}{ Formas indiretas } & Formas diretas \\
\hline $\begin{array}{c}\text { Formatos } \\
\text { Administrativos }\end{array}$ & Liturgias & Mercados & Hierarquias \\
\hline Personagens & $\begin{array}{c}\text { Notáveis } \\
\text { diletantes }\end{array}$ & $\begin{array}{c}\text { Capitalismo } \\
\text { aventureiro }\end{array}$ & $\begin{array}{c}\text { Burocracia } \\
\text { moderna }\end{array}$ \\
\hline $\begin{array}{c}\text { Mecanismos de } \\
\text { Coordenação }\end{array}$ & Confiança & Preços & Autoridade \\
\hline $\begin{array}{c}\text { Modos de } \\
\text { Interação }\end{array}$ & $\begin{array}{c}\text { Intensa fricção e } \\
\text { incerteza na } \\
\text { colaboração dos } \\
\text { notáveis }\end{array}$ & $\begin{array}{c}\text { Maximização dos } \\
\text { rendimentos. } \\
\text { Flutuações e } \\
\text { falhas de mercado }\end{array}$ & $\begin{array}{c}\text { Impessoalidade, } \\
\text { predictibilidade e } \\
\text { insulamento }\end{array}$ \\
\hline
\end{tabular}

Em uma administração de tipo honorário, ademais, a consideração das "circunstâncias" e da "pessoa" não se poderá evitar, visto que a fonte da autoridade dos notáveis residirá em sua capacidade de manipulação de redes múltiplas de lealdade e, sobretudo, em seu "prestígio", ou seja, sua capacidade de atender as expectativas de sua clientela (Eisenstadt e Roninger, 1984).

Imerso em redes cruzadas de pertencimento, o desempenho diletante da administração revelará afinidades eletivas com o cunho notadamente pessoal do conjunto das demais relações vigentes numa sociedade dessa natureza. A universalização e a impessoalidade que a administração formal supõe tenderão a ser traduzidas na particularização de amici e inimici, tornando indiscerníveis as diferenças entre justiça e vingança. $\mathrm{Na}$ esfera dos "sentimentos morais" estão ainda ausentes as precondições que permitiriam a transformação de simpathy em respect (Smith, 1984; Larmore, 1987, pp. 59-63). A atitude "profissional" de rigorosa obediência a um poder público abstratamente definido será aqui altamente problemática, se não improvável.

A formação dos Estados modernos, como sugeriu Norbert Elias, é resultado de processos simultâneos de pacificação social e intensificação de interdependências. Não seria estranho ao espírito daquele autor interpretar tais processos como uma extensão da esfera potencial de confiança para além dos limites dos contextos primários e adscritivos, possibilitando novas configurações de interação social. Tal extensão, entretanto, não eliminaria os problemas de construção e institucionalização de redes sociais de confiança, dado que o aumento da complexidade social implica, precisamente, o exacerbamento de novas formas de estranheza, intransparência e indeterminação (Elias, 1984).

Em um sentido mais geral, relacionado ao problema do kriterion do conhecimento, trust poderia ser interpretado como o "cimento do universo" que imuniza a ordem da common life em face da possibilidade da vertigem cética à vista da contingência da ordem do mundo (Hume, 1978, pp. 180-274). O conjunto de suposições taked for granteddo hábito e da crença que regem o devir ordinário do mundo permite aos seres sociais ir além da informação discreta disponível e generalizar expectativas de comportamento, tornando o mundo social mais previsível e calculável (Miztal, 1996, pp. 102-156).

Em um sentido mais limitado, mais sociológico, confiança poderia ser tematizada como uma das 
formas disponíveis aos sujeitos sociais de lidar com a liberdade alheia. $\mathrm{Na}$ vida social, a incerteza acerca do comportamento alheio nunca pode ser totalmente eliminada. As inumeráveis e específicas formas de interação social comportam graus variáveis de conhecimento e ignorância (Simmel, 1950, pp. 307-316).

Problemas de confiança emergem, sobretudo, em situações de interação estratégica em que um lapso de tempo separa as prestações e contraprestações de uma relação de troca. Crédito, dádiva e cooperação são tipicamente dependentes do tecido de confiança das relações interpessoais. No vocabulário de Luhmann, confiança permitiria uma estabilização contrafactual de expectativas em situações de contingência exacerbada. Na impossibilidade de estabelecer previsões seguras sobre que curso tomarão as ações do outro, confiança representa uma forma de aposta na manutenção de obrigações de natureza eminentemente moral (Luhmann, 1988; Silver, 1989).

Diferenças empíricas entre os padrões de cooperação de vários ambientes sociais e políticos poderiam, pois, ser compreendidas com o recurso à noção de confiança. Em contextos de natureza contratual, econômicos ou burocráticos, as estruturas de informação e incentivos aos atores dependerão da presença ou ausência de confiança como um "lubrificante" da cooperação. Confiança é um mecanismo redutor da acidentalidade e contingência produzidas pela fricção.

No Brasil imperial tornar-se-á dominante um modelo clientelar de relações entre centro e periferia, sobreposto às redes hierárquicas formais, sustentado por um sistema de trocas cujas principais "moedas" serão fidelidades, serviços e mercês. Sendo tênue e remota a capacidade de monitoramento e imposição de sanções por parte do poder central e, simultaneamente, acentuada a imersão dos notáveis em um conjunto variado e flutuante de compromissos locais, a administração honorária será fonte de problemas particularmente graves de construção de solidariedades entre o poder central e o quadro administrativo.
A combinação de administração honorária e ordens de privilégio irá definir os limites do que o Estado será capaz de fazer ou exigir, seja em função dos compromissos que o diletantismo da administração faz supor, seja pela relutância dos súditos que a dureza e a desigualdade do encargo fazem esperar. Aos constrangimentos que as redes de obrigações morais locais impõem à administração honorária do recrutamento corresponderão, antes de tudo, certas limitações nos meios materiaisde administração que lhe são característicos, e que delimitam, em boa medida, seu espectro de possibilidades. Será precisamente a penúria da administração formal o principal impedimento ao processo de "expropriação" dos meios de administração desses notáveis (Franco, 1983, p. 121).

A latitude dos poderes discricionários desses notáveis, assim como suas possibilidades de manipulação dos critérios de isenção, fazem do recrutamento um poderoso instrumento de poder econômico e social. Os notáveis promovem uma tradução localdas ordens do governo régio, interpretando a seu modo o sentido das exigências das levas e instrumentalizando o recrutamento como elemento crucial na produção de clientelas e "favores" (Costa, 1995).

Liturgiase mercados, dada a indisponibilidade ou a precariedade de meios administrativos diretos, representarão os principais mecanismos alternativos de administração de prestações militares e fiscais. A realização direta das tarefas da taxação e do recrutamento exigiria um aparato de execução e monitoramento de que a Coroa simplesmente não dispunha. As capacidades administrativas do Estado dependerão, pois, principalmente de sua habilidade em mobilizar recursos através de meios externosà sua estrutura formal de administração.

\section{A economia moral do recrutamento}

O conde de Suzannet, viajante arguto e um tanto desdenhoso que por aqui esteve na década de 1840, relatou um episódio curioso e ilustrativo: 
Existe em Ouro Preto uma carta manuscrita da Província de Minas. Solicitei uma cópia de tal carta, que era necessária para minha viagem. O embaraço foi grande: alguns dos pontos que eu pretendia visitar não estavam marcados, e tive de recorrer às cartas de Arrowsmith, Spix e de Brué para completar as lacunas. Exprimi em seguida ao presidente minha opinião sobre a negligência em que se encontravam serviços tão úteis a uma boa administração. Em um país onde tudo se assemelha à aventura, me respondeu esse funcionário, é impossível obter indicações exatas. O governo brasileiro não tem meios de organizar o serviço administrativo como deveria, pois ele deve consagrar seus recursos a prevenir revoltas, ou as reprimir. (Suzannet, 1844, p. 84)

A desventura de Suzannet é reveladora não apenas das dificuldades de deslocamento e comunicação que afligem os viajantes em um país onde "tudo é aventura", e que devem atravessar léguas de sertões ermos, mas sobretudo da relação direta entre a precariedade dos instrumentos de controle burocrático e as circunstâncias em que se processa a administração. Indisponíveis indicações exatas e informações precisas, viajantes e governantes precisam confiar no incerto testemunho alheio a respeito de coisas, lugares e pessoas.

A intensificação dos intercâmbios sociais implica maior necessidade de meios de registro racional, corporificados na prática notarial e na prova documental, em que se possam distinguir claramente despacho burocrático e correspondência privada. Mapas, documentos, inquéritos, registros, estatísticas, codificações: toda administração moderna é uma gigantesca produtora de papéis nos quais parte considerável da vida social se vê refletida, e através dos quais os movimentos da população são mais ou menos conhecidos e regulados. Os documentos escritos passam a formar um imenso corpus de memória coletiva (com seus próprios labirintos e armadilhas, é certo), que permite à administração atingir alto grau de padronização de procedimentos e objetividade de julgamento, estabelecendo um cânon que a autonomiza, em certa medida, da recorrência do procedimento habitual baseado na tradição e do julgamento subjetivo baseado no arbítrio do funcionário.

Freqüentemente, faltarão à administração local no Império os requisitos mínimos para a execução ordinária das tarefas de uma administração letrada. Faltam, como deixa entrever profusamente a correspondência das autoridades inferiores, formulários, papéis, regulamentos, livros de registro etc. Os despachos realizam-se na própria residência do funcionário. As despesas são muitas vezes, em face da indispensabilidade das tarefas, feitas às próprias custas das autoridades e ressarcidas com dificuldade, posteriormente (Uricoechea, 1978, p. 159).

O resultado agregado das indisponibilidades do mundo liliputiano da administração local será a virtual imobilização do Leviathan. As estatísticas oficiais sobre magistratura, efetivos da Guarda Nacional e Exército, gastos orçamentários e divisão administrativa sofrerão de irremediáveis lacunas, que demonstram quão pouco o Estado é capaz de informar-se sobre suas próprias dimensões e rotinas.

Surpreende ao observador contemporâneo, sobretudo, a ausência da codificação dos procedimentos e o domínio do julgamento prudencial nas rotinas da administração. $\mathrm{Na}$ correspondência volumosa e detalhada da administração inferior, não apenas minuciosa nas descrições, mas freqüentemente acompanhada de densas reflexões pessoais, há enorme contraste entre a relativa simplicidade e univocidade das diretivas do governo central e a variedade das práticas administrativas que lhe serviam de resposta (Uricoechea, 1978, p. 169). Ao sentido literal das ordens sobrepõe-se a plurivocidade das interpretações, e no caminho ordenamentos imperativos transformam-se em mera sugestão. Como comentará o chefe de polícia da Província de Minas:

Os cargos onerosos à que nenhuma recompensa suaviza, são aceitos e exercidos entre nós como um sacrifício levado as àras da Pátria, pelos cidadãos a quem são conferidos. D'ahi a crença muito natural de que certos empregos há como esses à que me refiro, em que os cidadãos que o exercem fazem favores a quem lhes delega certa somma de poderes, e que pois, muitas das exigências que se faz, são encaradas como impertinentes. 1

Falta, sobretudo, gente qualificada a quem confiar a administração local. O absenteísmo judicial é particularmente acentuado, tanto em razão dos juízes que ocupam, simultaneamente, as legislaturas provincial ou geral, quanto de outros que se licenciam pelas mais variadas razões. Muitos dos cargos que deveriam ser ocupados por 
letrados profissionais, em conseqüência, são, na verdade, exercidos pornotáveis diletantes (Uricoechea, 1978, p. 113; Flory,1986, p. 73). É o caso dos juízes substitutos, seis para cada distrito, criados pela reforma do Código de Processo, que atuariam no lugar dos juízes distritais na sua ausência ou impedimento. A lei especificava que deviam ser cidadãos do lugar "notáveis por sua fortuna, inteligência e boa conduta". Apesar de remunerado, o cargo não exigia educação legal formal (Graham, 1990, p. 65).

Estavam ausentes também, lamentavam as autoridades, as condições materiais mínimas para o exercício da ordem: acusam os oficiais que as cadeias estão em ruínas, faltam ferros e correntes para conduzir recrutas e galés, não há com que alimentar e tratar os presos. $\mathrm{O}$ agente do recrutamento de Januária, no sertão de Minas, por exemplo, se vê na precisão de pedir ao sargento instrutor da Guarda Nacional para prestar-se ao serviço de receber os recrutas em seu quartel, "huma vez que a Cadêa não tem cômodo a bem de muito baixa, que com facilidade poderiam evadirçe". . Faltam também armas e uniformes aos guardas nacionais, assim como aos permanentes dos corpos municipais e provinciais.

Tal penúria irá contrastar com a resolução de fazer valer a sua vontade daqueles que se julgam ofendidos pelas exigências do Estado. Presos e recrutas são tomados com facilidade das cadeias pelos seus parentes ou amigos, como se conta de um incidente na vila do Tamanduá:

[...] a força de um grupo de Pai, Irmãos e parentes do mesmo recruta, o livraram da prisão, e passaram a desautorizar aos Officiais de Justiça, e ao mesmo Juiz, e finalmente vieram a Cavallo a porta do juiz sem respeito as Leis e o vilipendiaram com palavras, e ameaças d'armas, espingardas, pistolas e zagaias, o desafiando, dizendo "apareça o seu povo", e que vinham dispostos a matar, e morrer. $\underline{3}$

A precariedade material da administração e a ausência de regularidade nos serviços públicos mais essenciais combinam-se com o amadorismo dos funcionários, que desempenham múltiplas funções públicas e privadas. As ações policiais são improvisadas de momento, com pessoas comissionadas para certas ocorrências. A intervenção de notáveis locais e suas clientelas na manutenção da ordem é também prática corrente.

A situação dos corpos de polícia provinciais, a julgar pela Província de Minas, é também extremamente precária. Em 1873, o presidente daquela província assim justificava o fracasso na realização do recrutamento: "[...] A província não tem podido concorrer com o número de recrutas que lhe é distribuído annualmente, não porque deixe de existir grande pessoal em condições de prestar serviços no exército, mas por falta absoluta de força para capturá-lo."

A contingência da ação administrativa explica-se, sobretudo, pela dependência dos auxílios que provêm deliturgias e, subsidiariamente, do mercado. Não é apenas nas eleições que se recorre à colaboração de amigos, clientelas e "patuléias". A administração rotineira da ordem, policial, judicial ou do recrutamento, também depende desses auxílios. Administrar, sob tais condições, significa sobretudo formar coalizões, pactar e barganhar compromissos, devido "[...] à fraqueza da ação do governo em lugares remotos, em que ella mal se sente, e onde não se podem empregar outros meios que não sejam os de brandura, e quasi condescendência." (Relatório do Ministério da Justiça, 1850, p. 9).

A precariedade geral da administração, aliada à sua dependência de auxílios litúrgicos, implicou intensas dificuldades em institucionalizar a ordem pública. A fragmentação dos meios de violência significava, em última instância, que não podiam existir garantias suficientemente seguras de que as autoridades seriam mais poderosas que seus oponentes, que, aliás, dada a rotatividade dos partidos, poderiam estar no poder no dia seguinte. $\mathrm{Na}$ incerteza quanto à eficácia da ação das autoridades, comentava Eusébio de Queiróz, a população fraternizava-se com os malfeitores:

A população, disseminada por uma vastíssima superfície, mais depressa auxilia os malfeitores do que a força pública, porque o medo a obriga a tolerar, senão fraternizar com aquelles. Se são prezos, he logo de recear a fuga das prisões, o arrombamento dellas, como em diversos lugares tem acontecido. Não há exageração no quadro que acabo de traçar, todo delineado sobre informações oficiaes recebidas. (Relatório do Ministério da Justiça, 1850, p. 7) 
$\mathrm{O}$ recurso a alternativas indiretas de governança pelo mercado também será freqüente. As obras públicas que as municipalidades desejam realizar serão dependentes de subscrições, loterias, contribuições e donativos (Franco, 1983, p. 119). Em certas situações, emergirão curiosas interações entre "subscrições voluntárias" e encargos. Fernando Dores Costa mostrou, em outro contexto, como o Estado português do século XVIII fora capaz de obter generosas "contribuições voluntárias" da comunidade mercantil de Lisboa, mediante uma bem estudada economia de ameaças e promessas de mercês (Costa, 1992). Lógica semelhante parece operar aqui. Jeanne Berrance de Castro narra que no Rio de Janeiro, por exemplo, os destacamentos da Guarda Nacional passaram a recair, primeiramente, sobre aqueles que se haviam recusado a contribuir para uma subscrição "voluntária", que tinha por objetivo pagar os soldos do corpo dos municipais permanentes, com o fim de aliviar o serviço dos mesmos (Castro, 1979, pp. 42-43).

$\mathrm{Na}$ atividade do recrutamento, sobretudo, o uso do dinheiro é fator decisivo. Os próprios agentes do recrutamento, tão temidos, devem sua particular voracidade à peculiar estrutura de incentivos a que estão sujeitos, sendo remunerados por "peça", à base de $4 \$$ por recruta e $6 \$$ por voluntário. Como advertia o agente da vila do Tamanduá:

Tenho empregado alguns espias, que os julguei habeis, em observações de individuos sujeitos ao Recrutamento, com promessa de certa gratificação particular por cada recruta que encaminharem a capturar-se; esta medida hé a única que jugo produzirá o desejado effeito, pois já no transacto recrutamento vi-me na precisão de lançar d'ella mão, e foi profícua. 5

A carência primeira que bloqueia a racionalização das rotinas administrativas, e em particular os processos de recrutamento, deriva do desconhecimento dos contornos do território e população, aquilo que o historiador Antônio Manuel Hespanha (1986, p. 86), ao estudar o Portugal barroco, chamou de horizontes de invisibilidadeda população. A ampliação das capacidades extrativas e regulatórias do Estado esbarra na sua incapacidade de realizar censos, registros civis, cadastros rurais, padronizar pesos e medidas, controlar fluxos de moeda falsa e, em conseqüência, tributar, vacinar e recrutar de forma eficiente e eqüitativa.

A "contagem das almas" é tarefa que tradicionalmente cabe à Igreja, mas sua instrumentalização para fins seculares esbarra em obstáculos vários. Mesmo a Igreja tem dificuldades em registrar e sacramentar os ciclos vitais da vida e da morte dos seus fiéis mais distantes. Arcaísmos da estrutura social e política do país, tais como a religião do Estado, a administração pública baseada nas divisões territoriais eclesiásticas, a ausência do casamento civil, o sistema eleitoral dependente da organização paroquial, faziam dos padres elos essenciais da cadeia administrativa. $\mathrm{Na}$ ausência de suficiente pessoal letrado e na suposição de maior respeitabilidade e alguma neutralidade, um conjunto considerável de funções estranhas ao cuidado das almas será atribuído ao clero pelo Estado, tais como a elaboração de listas de população, a participação nas mesas eleitorais, o registro de terras e mesmo o sorteio para o recrutamento. A dualidade de suas lealdades, entretanto, será algo problemática, e mesmo, como se verá quando da questão religiosa, potencialmente explosiva.

Um bom exemplo das dificuldades que o Estado imperial encontra em acompanhar os movimentos da população está no destino da Lei do Registro Civil e do Censo Geral do Império, de 1851. A tentativa de laicização dos registros de nascimentos, casamentos e óbitos provocará resistências veladas em certas regiões, violentas em outras. Ela será o estopim da pouco lembrada Guerra dos Marimbondos e do Ronco da Abelha, como ficariam conhecidos os levantes populares contra o registro civil e o censo no interior de Pernambuco, Paraíba, Alagoas, Sergipe, Ceará e Minas Gerais, entre dezembro de 1851 e fevereiro de 1852.

Os mais graves episódios da revolta seriam registrados em Pernambuco. Uma mesma pauta de ação coletiva repete-se em praticamente todas as localidades atingidas pelo movimento. Homens e mulheres invadem as igrejas para protestar contra o novo regulamento, rasgam os editais e intimidam os juízes de paz e as autoridades policiais para que não ousem executá-lo. Nos casos mais graves, seguemse conflitos com a força pública, com mortos e feridos. 
Em Pau d'Alho, por exemplo, queixa-se o povo de que "sem certidão delles [os escrivãos] não se poderá fazer uma criança christã", revelando profunda ruptura na "economia sacra" da imaginação popular. Outros elementos de natureza mais profana, entretanto, combinavam-se também nos motivos dos "marimbondos" insurgentes. Se de um lado os párocos eram veladamente hostis ao registro civil, que lhes ameaçava tomar emolumentos, de outro a população desconfiava sobretudo das intenções do legislador. O rebatismo do regulamento como "Lei do Cativeiro" pelos insurgentes revelava apreensões de que os registros pudessem, de algum modo, servir a propósitos de escravização do "povo mais miúdo" dos libertos e livres de cor.

A proximidade entre a lei que extinguia o tráfico negreiro e a lei do censo dava ainda maior plausibilidade aos temores de reescravização. ${ }^{6}$ Em Muribeca, Pernambuco, o povo argumentava que a lei "tem por fim reduzir à escravidão as crianças que nascerem do primeiro do corrente em diante" (Palacios, 1989, p. 20). O juiz de Pau d'Alho, na mesma província, declarou ainda mais taxativamente: "O motivo pelo qual o povo se ostenta tão descontente e ameaçador, he porque diz que as disposições do decreto tem por fim captivar seus filhos, visto que os ingleses não deixam mais entrar africanos." (Palacios, 1989, p. 46).

A Lei do Registro Civil e do Censo será prudentemente esquecida pelo Estado imperial. Nesta como em muitas outras ocasiões no século XIX, os limites da intervenção do Estado serão demarcados pela "arte da separação" das reações dos atingidos ou interessados. O episódio dos "marimbondos", embora tenha constituído a mais violenta reação às tentativas de realização do censo de que se tem notícia durante todo o século XIX, não representava caso isolado. No varejo, o Estado imperial continuava encontrando grandes dificuldades em obter estatísticas e realizar censos populacionais (Ourém, 1885, p. 15). Além das dificuldades gerais de coordenação, de recursos e de pessoal que a tarefa de obter estatísticas censitárias em um território desmesurado evidentemente implicava, a experiência da lei de 1851 revelava ainda a operação de micromotivos daqueles que adivinhavam os propósitos a que os registros poderiam servir.

O temor do recrutamento representava o mais poderoso incentivo à omissão, à falsificação ou à destruição de informações. Durante a década de 1830, por exemplo, o governo provincial mineiro tentaria, com grandes esforços, produzir um censo provincial. Um juiz de paz assim relacionava os obstáculos que encontrara na obtenção das listas nominativas:

Cumpre-me Informar, a V. S. as Ilegalidades e vicios q' pr. vezes encontrei nas mencionadas relaçoens humas falsificadas a saber com mtas. faltas de Peçoas athé aqui conhecidas q' não estavam arroladas e foram pr. mim ademetidas e outros Informantis, alem de se ter mandado huma e mais vezes aos mmos. Inspetores Reformar as Listas, com mto. custo podisse obter o No. de quinhentos e sessenta, e sete fogos qdo. este No. hé muito demenuto, a População do Destricto q'pende esta falta, da Crassa Ignorancia dos Inspetoris Principalmtes. aquellis q' abitam pa. as Mattas do Jacori onde sendo mto. povoado, foi donde veio com maior demenuiçào pello Terrivel abuzo, em q'. estam os Povos em q'. o Governo Exige o No. de Povos pa. Trebutar ao povo, ou pa. oRecrutamento. 7

É de supor que o fenômeno tenha sido mais generalizado do que parece à primeira vista e, provavelmente, não restrito apenas às populações rurais. Não seria também exclusivo do Império. Christon Archer (1975, p. 239) indicou que, em 1800, um censo com objetivos de recrutamento na cidade do México havia conseguido declarações apenas daqueles que possuíam isenções legais. A população que se considerava ameaçada simplesmente desaparecia, de modo que não se sabia seu tamanho ou composição. Alan Forest (1989, pp. 43-98), em seu precioso estudo da conscrição napoleônica, também registrou os inúmeros conflitos e manipulações que os arrolamentos e a definição de quotas paroquiais de recrutas davam ocasião. Deve-se concluir, pois, que a relativa invisibilidade da população para fins administrativos não é resultado exclusivo de insuficiências técnicoburocráticas, mas sobretudo das estratégias de autoproteção dos "fogos".

A preparação de listas e arrolamentos servia, no Brasil imperial, a múltiplos propósitos de distribuição de privilégios ou encargos, dependendo das circunstâncias. Escravos, eleitores, votantes, jurados e guardas nacionais 
eram objeto de arrolamentos regulares. O recrutamento e a tributação também dependiam do conhecimento, ainda que precário, dos fluxos e das medidas de homens e coisas.

As disputas que se travavam em torno da qualificação dos guardas nacionais e, de forma ainda mais visível e barulhenta, da qualificação eleitoral revelavam como a aparentemente inocente tarefa de contar e listar os paroquianos era decisiva para definir destinos de indivíduos comuns, funcionários, partidos e gabinetes. A violência que invariavelmente acompanhava as eleições, assim como as dificuldades que procediam dos destacamentos dos guardas nacionais, dramatizavam situações em que, como no recrutamento, estavam em jogo estratégias múltiplas de evasão dos encargos e de captura das possíveis vantagens. Ser incluído ou excluído de determinado rol implicava definições cruciais de identidade social, de um lado, e acesso a privilégios ou encargos, de outro. De certa maneira, o uso de todos os expedientes para controlar e influenciar a atividade de produção de listas era consuetudinariamente reconhecido e legitimado.

Registros objetivos, procedimentos universalizantes e mecanismos aleatórios de seleção, no contexto de uma sociedade crivada de profundas assimetrias, laços de dependência e redes de proteção privada, tomavam sentido totalmente inverso a que idealmente deveriam servir. Manipulação nos processos de seleção, pressões ilegítimas de todos os lados e vulnerabilidade às influências externas cruzavam-se com a operação efetiva de eleições, formação de júri, de destacamentos da Guarda Nacional e de sorteio de recrutas. $\mathrm{Na}$ ausência de mediações institucionais adequadas e de um quadro administrativo insulado das lutas locais, faltavam as garantias essenciais de eqüidade e honestidade que permitissem a incerteza dos resultados.

Os conflitos de jurisdição e competências entre as várias ordens de funcionários seriam uma das fontes mais conspícuas de instabilidade e conflito no interior da administração imperial. Juízes de Direito, delegados, juízes de paz, comandantes da Guarda Nacional, assim como os párocos, representarão os pólos de aglutinação possível de coalizões locais, alinhando-se, freqüentemente, aos faccionalismos já existentes e os exacerbando.

Não se pode compreender a dinâmica e os limites do recrutamento sem tomar em conta que a estrutura administrativa que realiza a governança da prestação militar representa um dos principais obstáculos à sua efetividade. As diferenças nas geografias da mobilização de recursos e da sua extração faziam ainda decisiva a participação ativa dos honoratiores na administração do recrutamento, e, por essa razão mesma, objeto de contínua tradução local.

Independente das suas múltiplas formas, havia sobretudo uma enorme hostilidade ao serviço militar, uma "barreira occulta, e de sentimento sinistro", nas palavras do juiz de Direito de Minas Novas, o que tornava a tarefa particularmente perigosa. $\underline{8}$ No amplo recrutamento promovido na Província de Minas em 1839, por exemplo, o agente do recrutamento de Lavras encontrou naquele município uma "negra opposição as deliberações da lei". Um guarda municipal foi morto em uma emboscada a uma patrulha de recrutamento e foram ouvidos "mtos. tiros em pontos vizinhos a Va.". Foi encontrada, ademais, uma proclamação anônima contra o recrutamento, afixada no pelourinho. Os juízes de paz recusaram-se a auxiliar no recrutamento, argumentando que, se o fizessem, "iriam de certo morrer". O juiz de paz de Sapucaí informava que também se achava coato, pois por ter prendido certo recruta, foi ameaçado de "lho virem tirar a força, e ainda de o assassinarem". No Serro, um "miserável liberal" andava "seduzindo a mocidade a não assentar praça de voluntário".? Mais ou menos por toda parte, variando em forma e intensidade, acontecimentos semelhantes raramente deixariam de acompanhar o recrutamento. Ameaças, tiros e bofetadas, suborno e dissimulação faziam parte do arsenal de recursos de ambas os lados da luta que se travava em torno das levas.

Paradoxalmente, o sucesso da tarefa do recrutamento será dependente, justamente, e no mais alto grau, de sua imprevisibilidade. Segredo e simultaneidade serão recomendados como fatores decisivos para o sucesso do apresamento. Todos sabem que na ausência de quaisquer 
previsões distributivas, praticamente qualquer um pode ser objeto da caçada humana. À menor suspeita da aproximação do recrutamento, os possíveis recrutas se antecipam e desaparecem nos sertões. A população se vê tomada de pânico e as vilas tornam-se desertas. $\underline{10}$ Os recrutadores queixam-se, sobretudo, da lei eleitoral e da chamada aos voluntários, que sinalizavam aos que estão "nas circunstâncias" do recrutamento a tormenta por vir, fazendo-os perder as melhores ocasiões. 11

Os agentes do recrutamento, por sua vez, adaptam suas estratégias a este mundo hobbesiano, utilizando todas as ocasiões e pretextos possíveis para recrutar. A sua astúcia e os seus expedientes, contudo, só fazem por tornar a tarefa ainda mais odiosa e tirânica aos olhos da população. Um deputado mineiro, por exemplo, julgava que a particular aversão dos habitantes da província ao serviço militar derivava, justamente, de ardis dessa natureza tornados em modo regular de administração:

Lembro-me com algum pezar de um facto que nessa occasião [1824] foi praticado na Capital da Província: milicianos que tinham sido chamados para a função do Corpo de Deus, que vieram de Mariana e outros pontos para Ouro Preto, foram depois da festa de Corpus Christi recolhidos ao quartel, de onde marcharam para o Rio de Janeiro. Esta acto da Administração, que não louvarei, concorreu muito para tornar ainda mais odiosa a vida militar, porque entendeu-se que tinha sido um ato de traição chamar os milicianos para uma procissão, e depois metê-los dentro de um quartel para virem servir no exército. $\underline{12}$

Curiosamente, são os indivíduos mais difíceis de classificar e de encontrar o alvo preferencial dos recrutadores, seja por uma sorte de justificação que guia a tarefa, que se poderia definir como utilitarismo corporativo, que reserva o serviço das armas para os elementos "improdutivos" da sociedade, seja (paradoxalmente) pela maior probabilidade de sucesso da empresa, visto que tais elementos não se encontram sob o abrigo de redes sociais de proteção.

O recrutamento não se pode considerar, de modo algum, como uma atividade administrativa regular. Nele se lançam mão de todos os recursos possíveis, por vezes desesperadamente. A sua freqüência e o seu volume são episódicos, dependentes das necessidades de reposição da tropa, das emergências militares e dos humores políticos, e, portanto, variáveis segundo as circunstâncias e imprevisíveis nos seus resultados. Estão ausentes quaisquer mecanismos regulares de reposição das fileiras, e a falta de quaisquer registros prévios, tanto dos indivíduos aptos ao serviço quanto dos isentos, torna a tarefa altamente arbitrária, imprevisível e errática. Mesmo entre a elite política imperial não havia consenso sobre a questão. Em parecer no Conselho de Estado, por exemplo, o visconde de Albuquerque argumentaria que a tentativa de soltar recrutas não era crime, pois que o ato não se consignava no Código Penal. $\underline{13}$

Em circunstâncias extraordinárias, de guerra externa ou rebelião interna (aliás muito freqüentes até os fins da década de 1860), as cotas não se poderão cumprir apenas com os vagabundos, viajantes incautos ou pequenos criminosos, gente cuja falta ninguém sentia. Caberá ao juiz de paz e, depois de 1841, ao delegado ou subdelegado de polícia, em última análise, a espinhosa tarefa de definir aqueles que estão "nas circunstâncias" do recrutamento. $\mathrm{Na}$ ausência de critérios distributivos bem definidos para o recrutamento, visto que as Instrucões de 1822constituem guia ambíguo para a tarefa, que mais embaraça do que auxilia (um deputado a chamará de "Lei do não recrutamento", tal a quantidade das isenções que demarcava), as decisões de local justicenessa esfera serão altamente discricionárias. Pode-se vislumbrar a tópica de critérios "seletivos" efetivamente utilizada pelos juízes de paz nas duas únicas listas de indivíduos indicados para o recrutamento que fui capaz de encontrar.

Esses documentos são notáveis, pois revelam como o recrutamento se exerce em um mundo de formas de reconhecimento e identificação eminentemente pessoalizadas. Aqueles que estão "nas circunstâncias" do recrutamento são seres cuja identidade não se revela por si só, mas em relação a lugares ou parentes. Outros se nomeiam por apelidos cuja semântica indica $\mathrm{O}$ pertencimento ao mundo da aventura e valentia, como o dito "roda da fortuna". De outros, ainda, se indicam os pecados a que o recrutamento deve punir. As listas expost, relacionando os recrutas presos, incluem também justificações de natureza "moral" sobre os motivos do recrutamento, tais como "vive em público adultério", "diz 
que socorre a mãe mas vive em público concubinato", "aventureiro", "vadio de profissão", "carpinteiro, mas de mau comportamento"..$\underline{16}$

\begin{tabular}{|l|l|}
\hline $\begin{array}{l}\text { "Relação dos que estão Nas } \\
\text { circunstancias de Serem Recrutados. } \\
\text { Nomes. }\end{array}$ & $\begin{array}{l}\text { "Lista de praças que o Senr' } \\
\text { Captm de Manoel Pereira ha de } \\
\text { recrutar em consequencia das } \\
\text { Imperiaes ordens. }\end{array}$ \\
\hline Joaqm. Inacio & 1o. Flávio José de Faria \\
\hline Manoel Filho do Roda da Fortuna & 2o. José Joaquim \\
\hline Joaqm. Filho do Do. & 3o. Manoel Filho de Roza \\
\hline João Barboza, he Cazado purem não vive & 4o. Marianno Dias no Barro Alto \\
\hline com a Mulher -- esta trata de disquitarce & 5o. Pedro Cabelleira \\
\hline Candido Morador no Alto do Morro & $\begin{array}{l}\text { 6o. Francisco Rasgado (pr. } \\
\text { alcunha)"1ㅗ }\end{array}$ \\
\hline Filho de Joze Amaro."14 & \\
\hline
\end{tabular}

Tais indicações, ainda que sumárias, iluminam os mecanismos de tradução localque regem o recrutamento, e que constituem um conjunto de "regras não escritas" que se sobrepõe àsInstruções de $1822 \mathrm{Na}$ economia moral do recrutamento, por exemplo, distinguir-se-ão entre casados e "mal casados", filhos bons e maus, artífices industriosos e vadios etc. Em Campanha, por exemplo, justifica-se o recrutamento de certo indivíduo pelo fato de, embora sendo casado, não viver com a mulher, e sim em "[...] amizade illícita com uma viúva de boa família no distrito de Santa Catarina, lugar em que foi preso dilapidando os bens da mesma, e que já hia se passando para os dos orphãos".17

Paradoxalmente, mesmo as famílias apelam eventualmente ao recrutamento como recurso último de correção daqueles que ultrapassam os limites do aceitável. O recrutamento passa, então, a assumir um sentido moral positivo, substituto possível da vendetta para as famílias incapazes de fazer valer a sua honra. Em certo caso, por exemplo, o recrutamento era suplicado por uma mãe como modo de garantir a honra das filhas, ameaçada pelo próprio pai. $\underline{18}$ Em outro relato, é o pai que oferece um cavalo para conduzir o recruta ferido durante a prisão, "afim de se ver livre delle, não só por ter estorquido alguns pôcos animais que puçuia como pr. disobediente". $19 \mathrm{Em}$ outro caso, ainda, o recrutamento é reclamado como punição a um filho ingrato que havia cometido "as maiores hostilidades", unindo-se a outros "pa. tirarem da Fazenda de seo Pai todo gado vacum e Cavalar q'. podia pilhar". $\underline{20}$

Os prováveis recrutas, de outro lado, utilizam-se de enorme repertório de estratégias de evasão, legais ou ilegais. O recrutamento dá origem a complexas manobras de identificação e obscurecimento de distinções, num jogo de proporções obsessivas. Em 1874, o conselheiro Junqueira, sendo ministro da Guerra naquela ocasião, calculava que para fazer 2 mil recrutas sob o recrutamento forçado era necessário prender 20 mil cidadãos, tantos eram os que desertavam "em rota", eram liberados por isenções ou defeito físico ou quaisquer outras razões (Annaes do Senado, 1874, vol. I, p. 52). Paradoxalmente, o recrutamento provocava, ao mesmo tempo, enorme desorganização social e era ineficaz do ponto de vista das necessidades do Exército. A imensa friçãoque acompanhava o recrutamento fica evidente, num caso entre mil, no relato do agente de 
Jacuí que, esgotado pela tarefa de Sísifo que realizava, informava:

Tenho apprehendido quarenta e sete individuos (inclusive trez voluntarios) dos quaes, vinte e oito cheguei a qualificar, vindo a ter remettido para o Ponto da Campanha desaseis destes, e doze evadiram-se das prizões, em que se achavam; e bem assim dos dezenove, que perfazem o numero dos quarenta, e sete: huns tem-se soltado por apprezentarem realmente motivos de izempção; e outros tambem tem se evadido das prizoens antes de serem qualificados. Agora de proximo deixaram os Guardas Nacionaes fugir quatro da Cadeia de São Joaquim, e outros deixaram fugir a trez, que conduziam de Jacuhi para aquella Cadeia. 21

As alternativas de evasão eram múltiplas. De um lado, a legislação permitia algumas saídas de mercado. A Portaria de 28 junho de 1823 admitia que os milicianos recrutados para a primeira linha pudessem dar por si substituto, provavelmente regulando práticas informais já existentes. A reforma de 1837 ampliaria ainda mais a franquia, passando a permitir a substituição de qualquer recruta por indivíduo idôneo, ou comutação por meio de pagamento de $400 \$ 000$.

Na Europa, a institucionalização da substituição marcava a diferença fundamental entre o recrutamento do antigo regime e os novos sistemas do século XIX, que garantiam provisões de saída para as elites (Bohigas, 1968; Choisel, 1981). A substituição representava, minguadas as alternativas "cívicas", uma forma de "voluntariado" induzido, que se poderia contar com certa previsibilidade. Os custos da substituição, evidentemente, estariam sujeitos a flutuações de preços de acordo com as circunstâncias de paz e guerra. Influiriam nas taxas de substituição a disponibilidade de mercenários potenciais e seu entusiasmo pela profissão militar, e sobretudo a presença de alternativas de evasão mais baratas (Forest, 1989, p. 58).

Os limites da capacidade de incorporar voluntários e recrutas faziam a substituição possível, e mesmo desejável, de um ponto de vista pragmático. Não se tratava de alteração da origem social dos recrutas, mas da circunstância de as isenções não se fazerem mais sem contrapartida. Tratava-se, sobretudo, do estabelecimento de um compromisso que permitisse aos ricos pagar pela liberação de seus filhos (e, portanto, taxá-los) e evitar ocommerce d'hommes informal, praticado pelos próprios agentes recrutadores (Levi, 1997, pp. 80-133).

A institucionalização de um mercado de substitutos no Brasil imperial esbarrava, no entanto, em três problemas fundamentais. Os dois primeiros diziam respeito a problemas de legitimação, o último ao modo de operação. Primeiro, a substituição representava, claramente, uma opção divisiva. Ela dramatiza a dependência entre a distribuição existente de riqueza e a distribuição dos encargos (Calabresi e Bobbitt, 1978, pp. 81-128). A crítica mais persistente contra ela seria o favorecimento dos ricos, transferindo o peso do serviço aos mais pobres.

Em segundo lugar, havia um argumento de natureza política: a substituição "desnacionalizava" o Exército, ao fazer com que o dever cívico dos cidadãos se cumprisse por soldados mercenários, ou talvez ainda pior, por libertos (Cavalcanti, 1871). Em terceiro lugar, e por certo mais decisivamente, a existência de inúmeras outras alternativas de saídade menor custo limitava as possibilidades de estabilização de um mercado dessa natureza. A lei do sorteio de 1874 , que permitia a substituição pessoal, seria acompanhada da formação de pelo menos uma companhia de seguro ao recrutamento, que se dedicaria à procura de substitutos para os seus segurados que tivessem o infortúnio de ser sorteados. $\underline{22} \mathrm{Nada}$ sabemos acerca do funcionamento efetivo de tal companhia, mas o fracasso do Estado imperial em implementar o sorteio certamente tornou seus serviços desnecessários aos seus clientes potenciais.

A mobilidade e a fluidez da população livre pobre em face das imensidões da "fronteira aberta" tornavam o recrutamento tarefa particularmente complexa e difícil. O "povo miúdo" muda de domicílio com facilidade e o temor do recrutamento encontra-se entre as principais razões para a errância contínua das gentes. Os fugitivos, ademais, contam com ampla cobertura da população local. As tentativas de controle da mobilidade da população, por meio da emissão de passaportes, seja pelos juízes de paz, seja pelas autoridades policiais, têm efeito diminuto. $\mathrm{O}$ 
agente do recrutamento para a região de Rio Pardo relatava em 1839, algo desanimado, que

Os embaraços mais salientes para se efetuar o encantado recrutamento n'este termo são imensos, pois se vê desleixos de alguns juízes de paz, omissões de outros e o embaraço ainda mais poderoso é que aqueles indivíduos que se acham nas circunstâncias de serem recrutados estão retirados, ou emigrados das povoações, e roças, e entranhados pelos vastos matos, sustentando-se em frutas, e raízes silvestres, preferindo uma vida tão triste, e lambujenta, à honra, e prazer, de servirem a Patria necessitada. $\underline{23}$

Se a simples fuga não é possível, no entanto, ou mostra-se arriscada, resta ainda ao provável recruta tentar adequar-se às circunstâncias que permitem isenção ao recrutamento. $\mathrm{O}$ recurso aos casamentos extemporâneos será um dos ardis mais utilizados pelos recrutas. $\underline{\underline{24}}$

$\mathrm{Na}$ manipulação dos critérios de isenção, os ardis dos recrutáveis mostravam-se particularmente variados e inventivos. Os títulos de estudante e de guarda nacional (depois de 1831), o último sobretudo, seriam particularmente cobiçados, pois permitiam sólidos fundamentos nas demandas por isenção. Declarações que alegavam idade insuficiente, doenças incuráveis, atividade profissional isenta, arrimo de família também abundavam, mas eram quase invariavelmente contestadas pelos agentes recrutadores, produzindo verdadeira guerra de ofícios em que se afirmavam e negavam evidências, testemunhos e contra-evidências. Como último recurso, alguns desesperados recorriam à automutilação, evidência terrível e indiscutível.

Se a fuga ou a adequação às isenções se mostrasse impraticável, a opção seguinte poderia ser a resistência, individual ou coletiva. Em grande parte dos casos de resistência armada efetiva, o incauto provável recruta contará com o auxílio de seus parentes ou de patronos poderosos. Em certas circunstâncias, entretanto, fazem-se valer laços mais horizontais forjados no calor da hora.

A repugnância ao serviço militar acompanhará os padrões característicos de outras formas de resistência a prestações exigidas pelo Estado, seja na forma de taxação, seja na extensão das capacidades regulatórias de uma forma geral. As pautas de ação coletiva combinarão tradições de resistência baseadas na honra familiar e navendetta com a destruição de registros e o bloqueio à ação dos oficiais públicos. O "rasga listas" será uma forma de resistência comum a várias esferas de intervenção estatal em que a produção de registros se mostra decisiva para novas formas de prestação. Ela não diferirá substancialmente, em suas estratégias, da quebra das coletorias, dos pesos e medidas, dos protestos contra o registro civil, ou dos cemitérios seculares.

\section{NOTAS}

1_ANRJ. IJ1 631. Relatório do chefe de Polícia. 15 de janeiro de 1866, fl. 120.

2 APM. SP. PP1 15, Cx. 14, Doc. 12. Agente do recrutamento. Januária, 1836.

3 APM. SP. Cód. 211. Juiz municipal de Tamanduá. 5 de abril de 1839.

4 ANRJ. IG1 215. Ofícios da Presidência da Província de Minas Gerais dirigidos ao Ministério dos Negócios da Guerra nos anos de 1870 a 1883. 8 de abril de 1873. Doc. 92.

5 APM. SP. Códice 237. Agente do recrutamento. Tamanduá, 13 de janeiro de 1839, fl. 08.

6 Os temores não eram absurdos. Para tentativas efetivas de reescravização, ver Freitas (1994).

7 APM. SP. PP 118 , Cx. 107. Juiz de paz do Distrito da Penha. Diamantina, 13 de agosto de 1840 .

8 APM. SP. PP1 18, Cx. 02, Doc. 01. Juiz de Direito. Relatório sobre a situação da Justiça na Comarca de Minas Novas. 1833.

9 APM. SP. Códice 237. Fls. 13 (Lavras), 31 (Serro) e 52 (Sapucaî). 1839.

10 APM. SP. Códice 13, fl. 188. Plano de recrutamento para a Provincia de Minas, offerecido por João José Lopes Mendes Ribeiro, e approvado por S.M.I. Ouro Preto, 1822.

11 APM. SP. Códice 237, fl. 39. Rio Preto, 18 de janeiro de 1839.

12 Annaes do Senado do Império do Brazil (1874). Dias de Carvalho, sessão de 30 de julho de 1874. Vol II, p. 327.

13 ANRJ. SDA. Códice 292 [Vol. 1]. Registro de pareceres e consultas da sessão de Marinha e Guerra do Conselho de Estado, relativos a negócios da repartição da Guerra. 5 de fevereiro de 1855. 
14 APM. SP. PP 115 , Cx. 15, Doc. 14. Agente do recrutamento. Distr. Boa Vista, 1836.

15 APM. SP. Códice 239, fl. 200. Juiz de paz de Carmo do Campo Grande (Lavras). 18 de agosto de 1839

16 APM. SP. PP 1 15, Cx. 15, Doc. 6. Relação nominal de recrutas forçados, pertencentes ao Município de Lavras, enviados pela agencia do mesmo, à Villa de S. João del Rei em 17 de maio de 1836; SP. Códice 237, fl. 91. Relação nominal dos recrutas que partem para a Cidade de S. João d'El Rey, extraida do Livro de Alistamento do Termo de Tamanduá (1837); CMOP. Códice 295-A. Registro dos voluntários e recrutados para o Exército da 1a. linha q' se reunirao na Villa de S. João d'El Rei em conformidade do Art 7o. das Instrucções dadas pelo Exmo. Presidente da Província (1836).

17 APM. SP. Códice 612. Campanha, 7 de fevereiro de 1856.

18 APM. SP. Códice 612. Baependy, 8 de fevereiro de 1856. Joan Meznar (1992) encontrou também inúmeros casos em que o recrutamento servia como punição a crimes contra a honra.

19 APM. SP. PP 115 , Cx. 14, Doc. 12. Agente do recrutamento. Januária, 1836.

20 APM. SP. PP 115 , Cx. 09, Doc. 03. Agente do recrutamento. Curvelo, 23 de fevereiro de 1836.

21 APM. SP. PP 115 , Cx. 07, Doc. 04. Agente do recrutamento. Jacuhy, 5 de agosto de 1836.

22 Coleção de leis, decretos e avisos do Império do Brazil. Decreto n. 5.984, de 8 de setembro de 1875. Approva, com modificações, os estatutos da Cia. de Seguro Mútuo sobre o Recrutamento.

23 APM. SP, Códice 238. Agente do recrutamento do Rio Pardo ao presidente da Província. 1839.

24 Cf., por exemplo, APM. SP. Códice 237, fl. 34. Tamanduá, 18 de setembro de 1839. Na França napoleônica, a isenção dos casados estimulava um mercado de "viúvas profissionais" e agenciadores de casamentos. Cf. Forest (1989, p. 51).

\section{BIBLIOGRAFIA}

ANNAES DO SENADO DO IMPÉRIO DO BRAZIL. (1874), Rio de Janeiro, Typ. do Diário do Rio de Janeiro. 4 vols.
ARCHER, Christon. (1975), "To serve the king: military recruitment in late colonial Mexico". Hispanic American Historical Review, 55, 2: 226-250.

BENDIX, Reinhard. (1978), Kings or people: power and the mandate to rule. Berkeley, University of California Press.

BOHIGAS, Nuria Sales de. (1968), "Some opinions on exemption from military service in nineteenth century".Comparative Studies in Society and History, 10, 3: 261 289.

BRADACH, Jeffrey e ECCLES, Robert. (1989), "Price, autority and trust: from ideal types to plural forms". Annual Review of Sociology, 15: 97-188.

BÜSCH, Otto. (1997), Military system and social life in old regime Prussia, 1713-1807. Nova York, Humanities.

CALABRESI, Guido e BOBBITT, Philip. (1978), Tragic choices: the conflicts society confront in allocating tragically scarce resources. Nova York, Norton.

CASTRO, Jeanne Berrance de. (1979), A milicia cidadã: a Guarda Nacional de 1831 a 1850. São Paulo, Cia. Editora Nacional.

CAVALCANTI, Bezerra. (1871), Recrutamento, pelo capitão .... Rio de Janeiro, Typ. Esperança.

CHOISEL, François. (1981), "Du tirage au sort au service universel". Revue Historique des Armées, 37: 43-60.

CLAUSEWITZ, Carl von. (1988), De la guerre. Paris, Minuit.

COSTA, Fernando Dores. (1992), "Capitalistas e serviços: empréstimos, contratos e mercês no final do século XVIII". Análise Social, 27, 116-117: 441-460.

(1995), "Os problemas do recrutamento militar no final do século XVIII e as questões da construção do Estado e da nação". Análise Social, 30, 130: 121-155. 
EISENSTADT, Samuel e RONINGER, Louis. (1984), Patrons, clients and friends: interpersonal relations and the structure of trust in society. Cambridge, Cambridge University Press.

ELIAS, Norbert. (1984), A sociedade de corte. Lisboa, Estampa.

FLORY, Thomas. (1986), El juez de pazy el jurado en el Brasil Imperial. México, Fondo de Cultura Económica.

FOREST, Alan. (1989), Conscripts and deserters: the army and French society during the revolution and empire. Nova York, Oxford University Press.

FRANCO, Maria Sylvia de Carvalho. (1983), Homens livres na ordem escravocrata. 2a. ed., São Paulo, Kairós.

FREITAS, Ludy Bieber. (1994), "Slavery and social life: attempts to reduce free people to slavery in the Sertão Mineiro, 1850-1871". Journal of Latin American Studies, 26, 3: 597-620.

GRAHAM, Richard. (1990), Patronage and politics in XIXth century Brazil. Stanford, Stanford University Press.

HESPANHA, Antônio Manuel. (1986), As vésperas do Leviathan. Instituições e poder político: Portugal, século XVII. Lisboa, Almedina.

HUME, David. (1978), A treatise of human nature. Editado por Selby-Bigge. Oxford, Oxford University Press.

KISER, Edgar. (1994), "Markets and hierarchies in early modern tax systems: a principal-agent analysis". Politics \& Society, 22, 3: 284-315.

LARMORE, Charles. (1987), Patterns of moral complexity. Cambridge, Cambridge University Press.

LEVI, Margareth. (1988), Of rule and revenue. Berkeley, University of California Press.
(1997), Consent, dissent, and patriotism. Cambridge, Cambridge University Press.

LUHMANN, Niklas. (1981), "The improbability of communication". International Social Science Journal, 33, 1: 122-132.

(1988), "Familiarity, confidence, trust: problems and alternatives", in D. Gambetta (ed.), Trust: making and breaking cooperative relations, Oxford, Blackwell.

MENDES, Fábio Faria. (1997), O tributo de sangue: recrutamento militar e construção do Estado no Brasil Imperial. Tese de Doutorado em Ciência Política, Rio de Janeiro, Instituto Universitário de Pesquisas do Rio de Janeiro (Iuperj).

MEZNAR, Joan E. (1992), "The ranks of the poor: military service and social differentiation in Northeast Brazil, 18301875". Hispanic American Historical Review, 72, 3: 335351.

MIZTAL, Barbara. (1996), Trust in modern societies. The search for the basis of social order. Cambridge, Polity Press.

OURÉM, Barão de. (1885), Quelques notes sur les bureaux de statistique au Brèsil. Communication faite à la Societé Statistique de Paris, par le Baron ... Pau, Pernambuco, Imprimerie Arêas.

PALACIOS, Guillermo. (1989), A "Guerra dos Marimbondos": uma revolta camponesa no Brasil escravista (Pernambuco, 1851-1852). Rio de Janeiro, CPDA/UFRRJ, mimeo.

RELATÓRIO apresentado à Assembléa Geral Legislativa na segunda sessão da oitava legislatura, pelo ministro e secretário d'Estado dos Negócios da Justiça, Eusébio de Queiróz. Coutinho Mattoso Câmara. Rio de Janeiro, Typ. Nacional, 1850.

SCHLUCHTER, Wolfgang. (1989), Rationalism, Religion, Domination: $A$ Weberian Perspective. Berkeley, University of California Press. 
SILVER, Alan. (1989), "Friendship and trust as moral ideals: an historical approach". Archives Europeénes de Sociologie, 30, 2: 274-297.

SIMMEL, Georg. (1950), "Knowledge, truth and falsity in human relations", in Kurt Wolff (ed.), The sociology of Georg Simmel, Nova York, Free Press.

SMITH, Adam. (1984), The theory of moral sentiments. Indianapolis, Liberty Fund.

SUZANNET, Comte de. (1844), "Le Brésil en 1844. Situation morale, politique, commerciare et financière". Revue des Deux Mondes, VII.

THOMSON, Janice. (1994), Mercenaires, pirates and sovereigns: state building and extraterritorial violence in early modern Europe. Princeton, Princeton University Press.

URICOECHEA, Fernando. (1978), O minotauro imperial. A burocratização do Estado patrimonial brasileiro no século XIX. São Paulo, Difel.

WEBER, Max. (1986), Economía y sociedad. Esbozo de sociología comprensiva. México, Fondo de Cultura Económica.

* Este artigo reelabora temas discutidos em minha tese de doutorado, O tributo de sangue: recrutamento militar e construção do Estado no Brasil imperial, defendida no Iuperj em 1997. 